Fukushima J. Med. Sci.,

Vol. 61, No. 2, 2015

[Original Article]

\title{
DOWN'S SYNDROME WITH NEONATAL ALLOIMMUNE THROMBOCYTOPENIA DUE TO HLA-A2 ANTIBODY
}

\author{
TOSHIHIKO NAKAMURA ${ }^{1)}$, TOMOAKI NOMURA ${ }^{1)}$, TAKASHI KAMOHARA ${ }^{1)}$, \\ HIDEHIRO TAKAHASHI ${ }^{1}$, DAISUKE HATANAKA ${ }^{1)}$, MICHIKO KUSAKARI', \\ MARI NAKAMURA $^{1)}$, KINUYO KAWABATA ${ }^{2)}$ and HITOSHI OHTO ${ }^{2)}$ \\ ${ }^{1)}$ Department of Neonatology, Japanese Red Cross Musashino Hospital, Musashino, Japan, ${ }^{2)}$ Department
of Blood Transfusion and Transplantation Immunology, Fukushima Medical University, Fukushima,
Japan
}

(Received July 28, 2015, accepted September 29, 2015)

\begin{abstract}
Anti-HLA antibodies reportedly exist in the one third of pregnant women. But few occurrences of neonatal alloimmune thrombocytopenia (NAIT) caused by anti-HLA antibodies have been reported. Here a male baby, who was admitted for low birth weight with Down syndrome (DS), was suffered from thrombocytopenia without transient myeloproliferative disorder (TMD). Positive reactions of HLA-specific antibodies were detected in maternal serum. Crossmatching tests between maternal serum and paternal platelets and lymphocytes were strongly positive. It is most conceivable that the previous pregnancy of the mother induced the production of anti-HLA-A2 antibody, which crossed the placenta and subsequently caused an NAIT in the case presented. This is the first case of DS with NAIT due to anti-HLA antibodies.
\end{abstract}

\section{INTRODUCTION}

Down syndrome (trisomy 21: DS) is the first described chromosome disorder and the most common viable autosomal trisomy, occurring in approximately 1 in 700 to 800 live births. The incidence of thrombocytopenia in neonates with DS is higher than that of in general population ${ }^{1)}$. In particular, thrombocytopenia below $150 \times 10^{9} / \mathrm{L}$ was approximately two-third of DS during the $1^{\text {st }}$ week of life $^{2)}$. Thus thrombocytopenia is one of the most common hematological abnormalities. Because neonates with DS have several hematological disorders such as transient myeloproliferative disorder (TMD) which occurs in $4 \%$ to $10 \%$ of neonates with DS, there may be associated complication of thrombocytopenia $^{3-5)}$. Approximately $20 \%$ of DS patients with TMD die, usually from hepatic or cardiopulmonary failure. Treatment with low-dose cytarabine can benefit high risk neonates with TMD. Differential diagnosis of thrombocytopenia in neonates with DS is very important for prognosis ${ }^{6 / 7)}$.

Neonatal alloimmune thrombocytopenia (NAIT) is one of the most common causes of thrombocytopenia and a clinical syndrome characterized by marked thrombocytopenia in the fetus and neonates, developing before or shortly after birth ${ }^{89)}$. NAIT is caused by fetomaternal incompatibility for platelet antigens. Incompatibility results in transplacental passage of maternal anti-human platelet antigen (HPA) antibodies, including anti-human leukocyte antigen (HLA) antibodies. Anti-HLA antibodies have been reported in $31 \%$ of pregnant women in a Caucasian dominant population ${ }^{10)}$ and in $9.4 \%$ of pregnant women in Japan ${ }^{11)}$. However, few reports have described NAIT resulting from anti-HLA antibody. The primary cause of NAIT has estimated to occur in 1 in 2,000 to 3,000 births in Caucasian populations $^{6 / 7) 12-14)}$. But in the Japanese population, NAIT occurs at the comparatively low level of approximately 1 in 5,000 to 10,000 births ${ }^{15) 16}$.

With DS, there has not been reported NAIT due to anti-HLA antibody. Only one case of alloimmune thrombocytopenia with DS due to anti-HPA antibody was reported $^{17)}$. We here report the first case of male Down's syndrome with NAIT which

Corresponding author: Toshihiko Nakamura, MD, PhD E-mail : toshi93778@musashino.jrc.or.jp

https://www.jstage.jst.go.jp/browse/fms http://www.fmu.ac.jp/home/lib/F-igaku/ 
was most likely due to HLA antibody of A2 specificity.

\section{CASE REPORT}

A baby boy with a birth weight of $2.032 \mathrm{~g}$ $(-2.43 \mathrm{SD})$, height of $44.5 \mathrm{~cm}(-1.51 \mathrm{SD})$, and head circumstance of $31.0 \mathrm{~cm}(-1.35 \mathrm{SD})$ was delivered by emergent caesarean section at 37 weeks because of variable cardiac deceleration. Apgar scores were 8 at $1 \mathrm{~min}$ and 8 at $5 \mathrm{~min}$. The mother, aged 37 years, was healthy and had been pregnant once and given birth once. She had no history of blood transfusions or autoimmune disease, and tested negative during routine pregnancy screening for both TORCH (toxoplasmosis, rubella, cytomegalovirus, and herpes simplex virus) infections and vaginal Group B Streptococcus. There was no maternal drug ingestion and her PLT count was normal during pregnancy and after delivery. Her first child was born without complication, so has not been examined the platelet count since birth. She had not been screened for DS at the first-trimester. A prompt spot diagnosis of DS was made in the baby with typical facial features and trisomy $21(47, \mathrm{XY},+21)$ was subsequently confirmed following chromosomal evaluation. The mother's complete blood count was normal and her blood cell type identical to newborn's blood cell type-O Rh (D) positive.

The initial PLT count on the peripheral venous blood sample was $45 \times 10^{9} / \mathrm{L}$ and no diffusely scat- tered petechiae were present (Table 1 ). The PLT count declined to a nadir of $24 \times 10^{9} / \mathrm{L}$ by the fifth day. There was no evidence of hemorrhage or other abnormal findings, such as hepatosplenomegaly, in an ultrasound scan of the brain and abdomen. Neither PLT transfusion nor gammaglobulin was used. Thrombocyto- penia spontaneously recovered after 3 weeks without clinical complications or the need for therapy (Fig. 1). A histological examination of the placenta and umbilical cord revealed no pathological findings.

\section{MATERIALS AND METHODS}

Blood samples from the patient were drawn by venipuncture after informed consent was obtained from his parents for further investigation of his cells and sera after 4 days of delivery. Also the blood samples of the parents' were collected after written informed consent was taken on the same day.

\section{Atni-Platelet Antibodies and Platelet Antigen typing}

To detect anti-platelet antibodies, a mixed passive hemagglutination (MPHA) assay was performed using a commercially available kit (ANTI-HPA·MPHA Panel, Beckman Coulter, US) with and without addition of chloroquine ${ }^{18)}$.

HPA typing was performed using a commercially available kit (WAKFlow HPA typing kid, Wakunaga, Hiroshima, Japan).

Table 1. Laboratory values on admission.

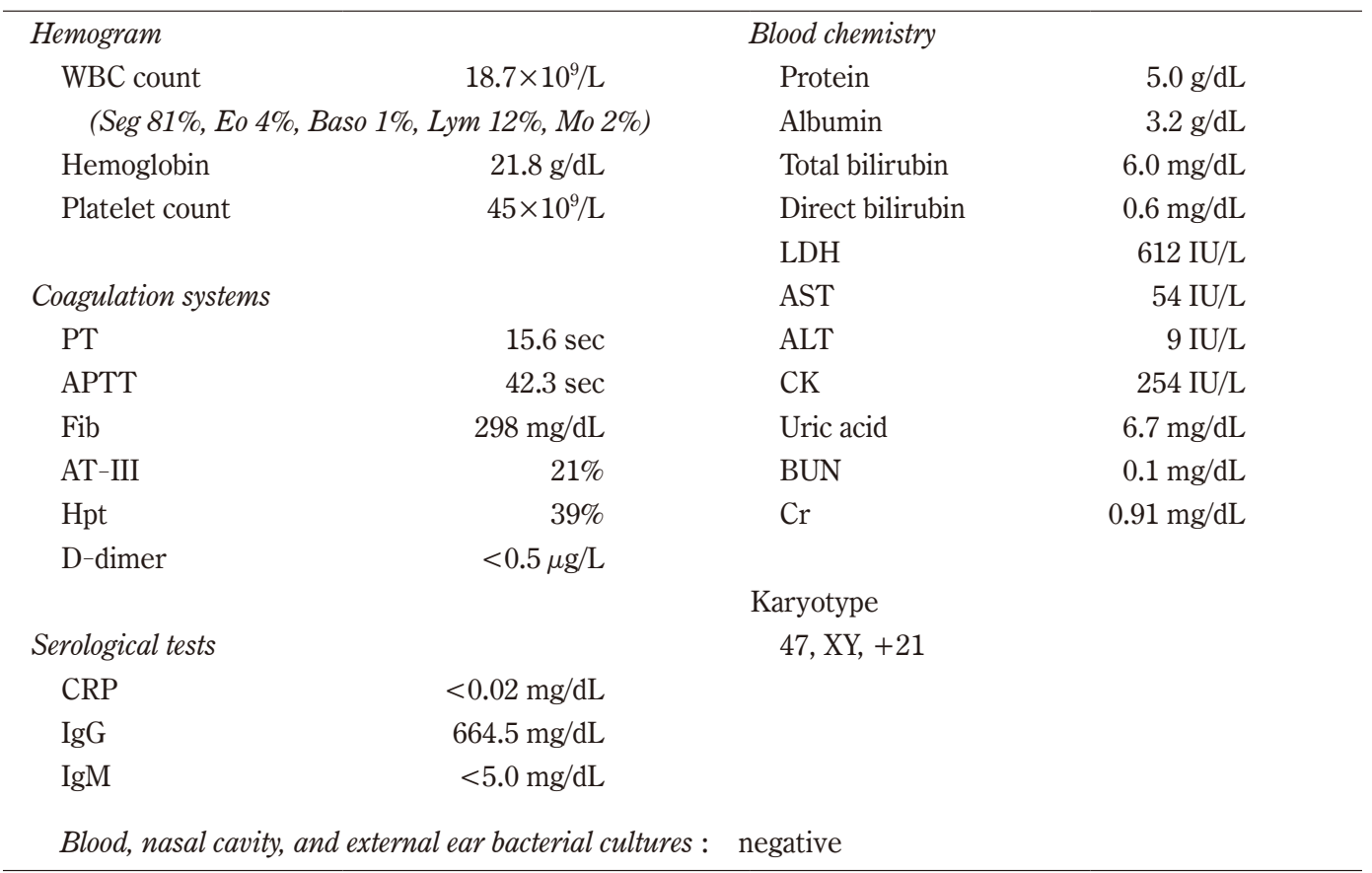




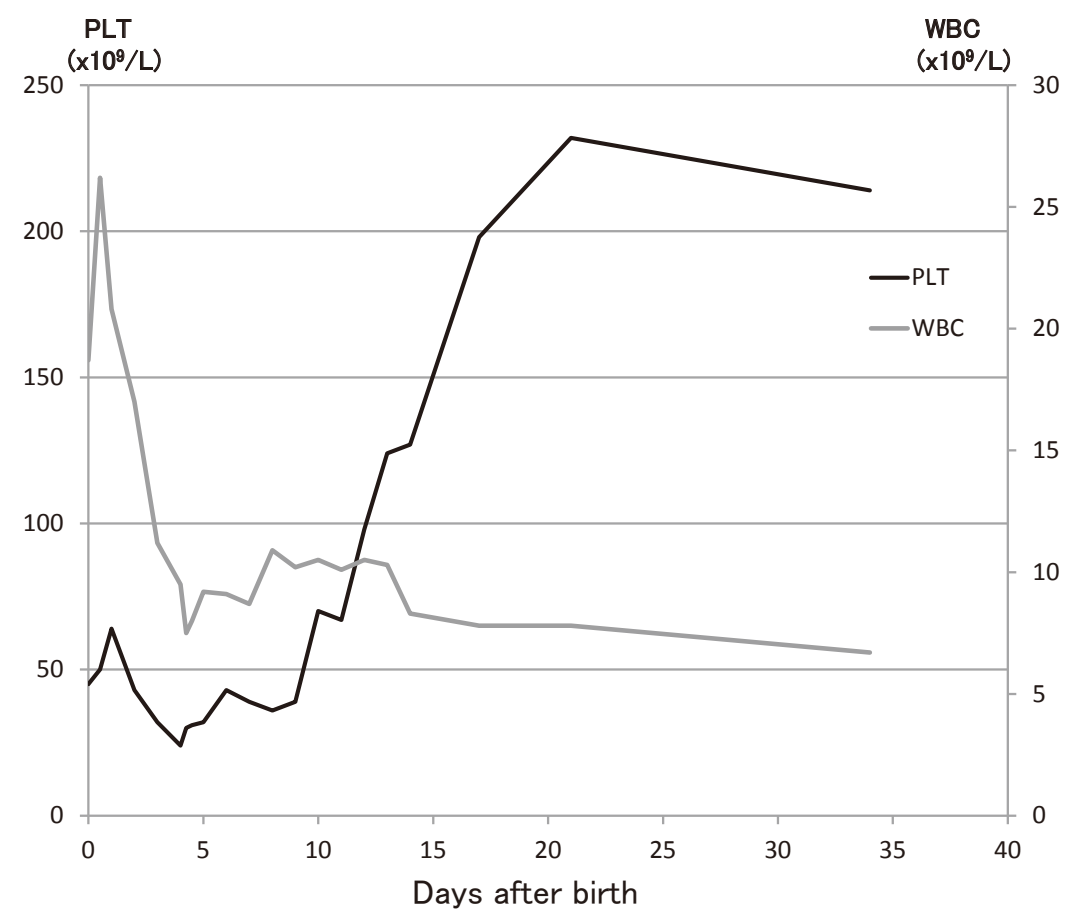

Fig. 1. Platelet and white blood cell counts during the patient's clinical course. The lines indicate platelet count (black line) and white blood cell count (gray line).

\section{Antibody Against HLA Class I}

The blood sample was screened for anti-HLA class I antibodies by Luminex ${ }^{\circledR}$ method using fluorescent beads coated with HLA-A, $-\mathrm{B},-\mathrm{Cw}$ antigens (WAKFlow HLA antibody MR ; Wakunaga, Hiroshima, Japan).

\section{Lymphocytotoxicity Assay for Anti-HLA Antibodies and HLA Typing}

To detect anti-HLA antibody and analyze its specificity, an anti-human Ig lymphocytotoxicity test (AHG-LCT) was performed using a panel of lymphocytes. To determine whether HLA antigens were inherited from the mother or father, DNAbased typing was conducted by polymerase chain reaction reverse sequence specific oligonucleotide (PCR-rSSO)-Luminex method (Genosearch HLA Kit, MBL, Nagoya, Japan) with a Luminex $100^{\mathrm{TM}}$ IS fluoroanalyzer, in accordance with the manufacturer's instructions.

\section{Cross-Matching Test}

With the AHG-LCT, a maternal serum was tested against lymphocytes from the father and lymphocytes with known HLA antigens. Neonatal platelets were not available for testing. Titer of each serum was tested by serial dilutions of the sample in PBS until a negative test result was ob- tained.

\section{RESULTS}

The mother's platelet count was $18.3 \times 10^{10} / \mathrm{L}$ 4 days after delivery, thus excluding unrecognized autoimmune thrombocytopenia with passive transfer of platelet antibodies to her baby.

Investigations (Table 2 ) confirmed the diagnosis of NAIT caused by anti-HLA-A2 / -B48 / -Cw8 and anti-HPA-3a antibodies. Regarding HPA- 1 to HPA-7, - 15, -21, and $\mathrm{Nak}^{\mathrm{a}}$ isoantigen, maternalneonatal HPA-3a mismatch was observed in this case. The MPHA with chloroquine-treated platelets was conducted to detect HPA antibodies ${ }^{19)}$. The MPHA with chloroquine-untreated platelets was used for detection of both HPA and HLA antibodies. In maternal sera, anti-HLA-A2 cross-reacting group antibodies were observed with chloroquine-untreated platelets but not with chroloquinetreated platelets. And from the result of crossmatch test between maternal serum and paternal platelets revealed that titer of the antibodies, when the MPHA was used for antibody detection, decreased from 1 in 256 to negative after chloroquine treatment.

So we have concluded in this case, neonatal thrombocytopenia was due to the transplacental passage of maternal HLA-A2 antibodies to the baby. 
Table 2. Investigations.

\begin{tabular}{|c|c|c|c|c|c|c|c|c|c|c|}
\hline $\begin{array}{l}\text { Platelet immunology } \\
\text { Genotyping: }\end{array}$ & & & & & & & & & & \\
\hline Antigen & HPA-1 & HPA-2 & HPA-3 & HPA-4 & HPA-5 & HPA-6 & HPA-7 & HPA-15 & HPA-21 & $\mathrm{NaKa}$ \\
\hline Maternal platelet & $\mathrm{a} / \mathrm{a}$ & $\mathrm{a} / \mathrm{a}$ & $\mathrm{b} / \mathrm{b}$ & $\mathrm{a} / \mathrm{a}$ & $\mathrm{a} / \mathrm{a}$ & $\mathrm{a} / \mathrm{a}$ & $\mathrm{a} / \mathrm{a}$ & $\mathrm{a} / \mathrm{b}$ & $\mathrm{a} / \mathrm{a}$ & $(+)$ \\
\hline Paternal platelet & $\mathrm{a} / \mathrm{a}$ & $\mathrm{a} / \mathrm{a}$ & $\underline{\mathrm{a}} / \mathrm{b}$ & $\mathrm{a} / \mathrm{a}$ & $\mathrm{a} / \mathrm{a}$ & $\mathrm{a} / \mathrm{a}$ & $\mathrm{a} / \mathrm{a}$ & $\mathrm{a} / \mathrm{b}$ & $\mathrm{a} / \mathrm{a}$ & $(+)$ \\
\hline Patient platelet & $\mathrm{a} / \mathrm{a}$ & $\mathrm{a} / \mathrm{a}$ & $\underline{\mathrm{a}} / \mathrm{b}$ & $\mathrm{a} / \mathrm{a}$ & $\mathrm{a} / \mathrm{a}$ & $\mathrm{a} / \mathrm{a}$ & $\mathrm{a} / \mathrm{a}$ & $\mathrm{b} / \mathrm{b}$ & $\mathrm{a} / \mathrm{a}$ & $(+)$ \\
\hline
\end{tabular}

Cross-match of maternal serum versus paternal platelets :

- Positive reactions between mother's serum and father's platelets, titer $\times 256$

- Negative reactions performed with chloroquine-treated platelets

Anti-platelet antibodies and platelet antigen typing with maternal serum

- MPHA ; positive and specific to anti-HLA-A2 and negative with chloroquine

- Luminex ; multispecific positive

HLA typing and antibody screen

Class 1 typing :

Mother: A11 A24 ; B13 B52 ; Cw10 Cw12

Father: $\underline{\mathbf{A 2}}$ A2 ; B61 $\underline{\mathbf{B} 48}$; $\underline{\text { Cw8 }}$ Cw12

Patient: $\underline{\text { A2 }}$ A24; $\underline{\text { B48 }}$ B52; $\underline{\text { Cw8 }}$ Cw12

Lymphocyte cytotoxicity test [LCT] :

- Multispecific HLA antibodies detected between maternal serum vs. lymphocytes with HLA-A, B and C antigens identified previously, titer $\times 32$

- Positive reactions between maternal serum vs. paternal lymphocytes, titer $\times 32$

\section{DISCUSSION}

This case describes NAIT in an asymptomatic, apparently healthy low birth weight infant except for DS. A thrombocytopenia was noted on the $1^{\text {st }}$ day of life and lasted until $18^{\text {th }}$ day of life. The lowest platelet count was $24 \times 10^{9} / \mathrm{L}$ recorded on the $5^{\text {th }}$ day of life. Clinical course of the disease was mild, without event hemorrhage or need for therapy. Except for thrombocytopenia, there was no clinical sign suitable to TMD, so any other examinations such as bone marrow aspiration were not done.

In Japan, the most frequent incidents of PHArelated NAIT are caused by HPA- $4 \mathrm{~b}^{20211}$. Although there was an HPA-3a mismatch between the mother and baby in this case, anti-HPA-3a antibodies ware not detected by the MPHA treated with chloroquine. We cannot explain why the antibodies were not detected in maternal sera. Ant-HLA antibodies have been reported in $31 \%$ of pregnant women ${ }^{10)}$. In 1984, Shibuya et al. described the first reported case in Japan of NAIT associated with HLA antibodies $^{22)}$. However, few reports have described NAIT resulting from anti-HLA antibodies. No significant relationship was observed between anti-HLA-anti- body and other disorders ${ }^{23)}$. To our best knowledge, there has been only one report of DS with NAIT $^{17)}$.

There are several causes of neonatal severe thrombocytopenia. Thrombocytopenia in affected neonates is often due to underlying illness such as sepsis, disseminated intravascular coagulation syndrome and respiratory distress syndrome or alternatively due to maternal factors such as pregnancy induced hypertension and gestational diabetes. Previously we reported that maternal anti-HLA antibodies were in close relation to neonatal thrombocytopenia, especially in small-for-gestational-age (SGA) infants, and that in these infants, those whose mothers were positive for maternal anti-HLA antibody had incidence of neonatal thrombocytopenia about 9 times greater than those whose mothers were not sensitized ${ }^{24)}$. Placentas associated with SGA infants were reported to have a high incidence of abnormalities, such as ischemic lesions and villitis of unknown etiology ${ }^{25)}$. So it is conceivable that such damaged placentas may induce the leakage of maternal blood with anti-platelet antibodies to babies. The baby in this case belongs to SGA infant, but it is conceivable that the relation of the genetic 
disorder rather than placental abnormalities is a subject for the cause of SGA ${ }^{26)}$. In 1992, Araki et al. reported that patients with HLA-DR2 antigens frequently produced HLA-antibody ${ }^{23)}$. According to additional study (data not shown), the DR typing of the mother was revealed DR2. It may be a reason to raise the production of HLA-antibodies. But the mechanism of thrombocytopenia is not yet completely clear.

Pediatricians including neonatologists who are involved in the care of patients with DS need to be aware of the associated bleeding tendency and other hematologic problems, as these patients will often require surgical procedures. So in patients with severe congenital hemorrhagic disorder and persistent thrombocytopenia, the medical history and a careful clinical examination are crucial for a correct diagnosis.

The cohort study in Japan revealed that antiplatelet antibodies were detected in $0.91 \%$ of the pregnant women and the immunization rates were clearly correlated with the number of pregnancies. Anti-platelet antibodies were found in only $0.19 \%$ of women in their $1^{\text {st }}$ pregnancy and in $1.97 \%$ of them in the $4^{\text {th }}$ or more pregnancies ${ }^{22}$. NAIT affects the first pregnancy and can cause intracranial hemorrhage, with a tendency for earlier and more severe thrombocytopenia in subsequent pregnancies ${ }^{27)}$. The parents in this case hope to have the $3^{\text {rd }}$ baby after having gone to Korea of paternal country. So we will expect to report the scrutiny results for this thrombocytopenia in order to take an in-depth cooperation to obstetricians in charge of the 3rd child of this family. We want to ensure the next safe birth and the $3^{\text {rd }}$ healthy baby.

\section{REFERENCES}

1. Thuring W, Tonz O. Neonatale Thrombozytenwerte bei Kindern mit Down-Syndrom und anderen autosomalen Trisomien. Helv paediat Acta, 34 : 545-555, 1979.

2. Henry E, Walker D, Wiedmeier SE, et al. Hematological abnormalities during the first week of life among neonates with Down syndrome : data from a multihospital healthcare system. Am J Med Genet A, 143 : 42-50, 2007.

3. Gamis AS, Smith FO. Transient myeloproliferative disorder in children with Down syndrome : clarity to this enigmatic disorder. Brit J Haematol, 159 : 277-287, 2012.

4. Hord JD, Gan JC, Whitlock JA. Thrombocytopenia in neonates with trisomy 21. Arch Pediatr
Adlesc Med, 149 : 824-825, 1995.

5. Miller M, Cosgriff JM. Hematological abnormalities in newborn infants with Down syndrome. Am Med Genetics, 16 : 173-177, 1983.

6. Al-Kasin F, Doyle JJ, Massey GV, et al. Incidence and treatment of potentially lethal diseases in transient leukemia of Down syndrome : Pediatric Oncology Group Study. J Pediatr Hematol Oncol, 24 : 9-13, 2002.

7. Lange B. The management of neoplastic disorders of haematopoiesis in children with Down's syndrome. Br J Haematol, 110 : 512-524, 2000.

8. Bassler D, Greinacher A, Okascharoen C, et al. A systematic review and survey of the management of unexpected neonatal alloimmune thrombocytopenia. Transfusion, 48: 92-98, 2008.

9. Kamphuis MM, Paridaans N, Porcelijn L, et al. Screenig in pregnancy for fetal or neonatal alloimmune thrombocytopenia: a systemic review. BJOG, 117 : 1335-1343, 2010.

10. King KE, Kao KJ, Bray PF, et al. The role of HLA antibodies in neonatal thrombocytopenia : a prospective study. Tissue Antigens, 47 : 206-211, 1996.

11. Enomoto T, Maruoka H, Hanagaki S, et al. Pregnancy-induced alloimmunization against platelet antigens : HLA and human platelet antigens (HPA). Jpn J Transfus Med, 46 : 467-473, 2000.

12. Murphy MF, Williamson LM, Urbaniak SJ. Antenatal screening for fetomaternal alloimmune thrombocytopenia : should we be doing it? Vox Sanguinis, 83(Suppl. 1) : 409-416, 2002.

13. Mueller-Eckhardt C, Keifel V, Grubert A, et al. 348 cases of suspected neonatal thrombocytopenia. Lancet, 1 : 363-366, 1989.

14. Taaning E and Skibsted L. The frequency of platelet alloantibodies in pregnant women and the occurrence and management of neonatal alloimmune thrombocytopenic purpura. Obstet Gynecol Surv, 45 : 521-525, 1990.

15. Murano I, Yoshii H, Kurashige H, et al. A case of neonatal alloimmune thrombocytopenia due to anti-human leukocyte antibody. Jpn J Pediatr Med, 33 : 285-288, 2001.

16. Kato T, Oya K, Sato Y, et al. Two cases of neonatal alloimmune thrombocytopenic purpura. Jpn J Transfus Med, 45 : 174, 1999.

17. Madani K, Kamphuis MM, Lopriore E, et al. Delayed diagnosis of fetal and neonatal alloimmune thrombocytopenia : a cause of perinatal mortarity and morbidity. BJOG, 119: 1612-16161, 2012.

18. Araki N, Naruse T, Bouike Y, et al. Chloroquine treated platelet soluble antigens for MPHA test. Jpn J Transfus Med, 37 : 801-810, 1991.

19. Edwards JM, Moulds JJ, Judd WJ. Chloroquine dissociation of antigen- antibody complex : a new 
technique for typing red blood cells with a positive direct antiglobulin test. Transfusion, 22 : 59-61, 1982.

20. Ohto H, Miura S, Ariga H, et al. The natural history of maternal immunization against foetal platelet alloantigens. Transfus Med, 14 : 399-408, 2004.

21. Nagao N, Taniue A, Tomita N, et al. Neonatal alloimmune thrombocytopenia due to anti-HPA and the incidence of HPA antibodies in pregnant Japanese women. Jpn J Transfus Med, 44 : 317-321, 1998.

22. Shibuya Y, Kobayashi T, Sato T, et al. Two cases of transitory neonatal alloimmune thrombocytopenia. Jpn J Transfus Med, 30 : 579-581, 1984.

23. Araki N, Naruse T, Bouike Y, et al. Relation between HLA-antigen and HLA-antibody production in patients subjected to frequent platelet transfusion. Jpn J Transfus Med, 38 : 740-747, 1992.
24. Koyama N, Nakamura T, Ohto H, et al. Association of neonatal thrombocytopenia and maternal anti-HLA antibodies. Acta Paediatr Jpn, 3 : 71$76,1991$.

25. Altshuler G, Russell P, Ermocilla R, et al. The placental pathology of small-for-gestational-age infants. Am J Obstet Gynecol, 121 : 351-359, 1975.

26. Lee PA, Chernausek SD, Hokken-Koelega AC, et al. International Small for Gestational Age Advisory Board consensus development conference statement : management of short children born small for gestational age. Pediatr, 111 : 12531261, 2003.

27. Conti FM, Hibner S, Costa TH, et al. Successful management of neonatal alloimmune thrombocytopenia in the second pregnancy : a case report. Einstein, 12 : 96-99, 2014. 